\title{
Modern Therapeutic Concepts of Early Breast Cancer
}

\author{
Michael Gnant \\ Department of Surgery and Comprehensive Cancer Center MUW/AKH, Vienna, Austria
}

This issue of BREAST CARE covers modern therapeutic concepts of early breast cancer - after all, all of us in the clinical and research breast oncology community work hard in order to ensure progress for our patients in this curable stage of the disease - following the principle 'the optimal way to cure is to avoid and prevent relapse and generalization'. Definitely, we are making progress: At least in central Europe, of all women diagnosed with breast cancer in the year 2014, more than $75 \%$ will die from something else (which for the breast oncologist is the - somewhat artificial - definition of cure from breast cancer).

With 3 out of 4 women diagnosed with early breast cancer cured, the concern of overtreatment clearly is an issue [1]. In fact, we have reached this point by adding therapies to previous standards, as well as implementing new therapies (with new side effects). Understandably we hesitate to abandon anything of our great progress - and in some areas of early breast cancer treatment the combination therapy overkill has gotten out of hand. An example: is it really justified to treat a patient with a $6 \mathrm{~mm}$ primary hormone-receptor positive and HER-2/neu overexpressing tumor with 6-8 cycles of adjuvant cytotoxic chemotherapy, followed by 1 year of anti-HER2 treatment, combined with at least 5 years of endocrine therapy? Without any adjuvant treatment and despite the partly unfavorable biological characteristics, this particular patient would look at an approximate $90 \%$ probability of 10 -year disease free survival, and despite the fact that with all the abovementioned treatments we might be significantly pushing this up to above $95 \%$ (which means halving her risk of relapse), the question remains: is it worth the price? The price is paid by the patient with all the tolerability issues she has to handle, with numerous visits to hospitals and offices, with concomitant investigations and the ever-involved fears - but a price must also be paid by society, which has to bear the cost for all these treatments. I am not in any way advocating therapeutic nihilism, but we have so far largely failed to find an evidencebased guidance for really balanced assessments, and several interesting tools that have been proposed [2] never really made it into routine clinical practice. Moreover, I have the sneaking suspicion that we often fail to completely inform our patients about the realistic numerical benefits of the treat- ments we propose; probably because of concerns they might not follow our advice.

The basis for accurate decision-making, however, is accurate knowledge: this is the purpose of focusing this issue of BREAST CARE on modern concepts of early breast cancer care. In their excellent review article on axillary surgery, Toralf Reimer and his colleagues concisely narrate the tale of a real revolution in breast surgery [3]: despite all the nice talk about personalized medicine concepts, no other field of clinical routine was even remotely as dramatically revolutionized as axillary surgery. What more than a hundred years ago started as a ground-breaking concept [4] that enabled modern surgical oncology by being more 'radical' (and thus understanding the 'regional' nature of the malignant disease), has recently been reduced in a step-wise manner: less surgery to the breast was followed by less surgery to the axilla and may even be pushed further to no surgery whatsoever for some patients [5]. Despite some severe concerns about methodology and trials details, axillary radiotherapy is also considered an alternative by some [6].

Michael Knauer and his colleagues from the ABCSG [7] provide an excellent overview on current concepts and recent trial results with respect to another clinically extremely relevant question of adjuvant endocrine therapy: how long to treat? While the introduction of tamoxifen therapy has increased survival rates still more profoundly than any other later innovation, we have constantly increased treatment durations: From 3 months to 6 months to 1 year to 2 years to 5 years, and data from the last decade suggest that 10 years may be most beneficial [8], at least for some patients. Is this trend necessitated by the nature of hormone-receptor positive breast cancer, or does it merely mirror our inability to identify those individuals who really need prolonged treatment durations (which unfortunately inevitably means prolonged exposition to therapy-related side effects)? Recently, several multigenomic assays have been described, proposing that we could identify who would be at persisting risk of late metastasis and who would not $[9,10]$, which provides hope that we can leave the policy of treating all for the benefit of a few.

Besides surgery and drug therapy, radiotherapy is a cornerstone of modern treatment of early breast cancer. Also in this

\section{KARGER}

Fax +497614520714

Information@Karger.com

www.karger.com (c) 2014 S. Karger GmbH, Freiburg

$1661-3791 / 14 / 0092-0085 \$ 39.50 / 0$

Accessible online at:

www.karger.com/brc
Univ. Prof. Dr. Michael Gnant

Comprehensive Cancer Center MUW/AKH

Medizinische Universität Wien - Universitätsklinik für Chirurgie

Währinger Gürtel 18-20, 1090 Wien, Austria

michael.gnant@meduniwien.ac.at 
field, great innovations have been achieved, but inevitably also leave us with the challenge to resolve the conundrum of overtreatment. While many of us have tried in randomized controlled trials to spare some patients with perceived low risk of local relapse after breast conservation the side effects and logistic burden of adjuvant radiotherapy, we so far have largely failed to accurately identify a subgroup for which no benefits could be recorded [11]. Sergio Maluta and his colleagues describe an alternative approach: rather than whole breast radiotherapy or no radiotherapy for women with a favorable risk profile, they apply intraoperative radiotherapy (IORT) [12]. This may at least minimize the logistical burden of irradiation. The concept of accelerated partial breast irradiation (APBI) definitely warrants further investigation other than delivering only the boost intraoperatively, APBI conceptually minimizes patient burden more consequently. It remains to be seen, however, how long-term local control results as well as objective long-term aesthetic assessments finally will play out, also in terms of the health economy perspective. For that reason, the authors correctly conclude that this approach currently should only be used in the framework of clinical trials.

While we all like to praise the era of individualized breast cancer therapy, we have to humbly acknowledge that - outside the field of HER2-overexpressing breast cancer - major progresses are, at least for the time being, usually achieved with breakthrough innovations for unselected patient populations. Clinical practice will, for now, have to remain based on guidelines and consensus recommendations [13] - the future has yet to arrive.

\section{References}

1 Gnant M, Steger GG: Fighting overtreatment in adjuvant breast cancer therapy. Lancet 2009; 374 : 2029-2030.

2 Gelber RD, Goldhirsch A, Cavalli F: Quality-oflife-adjusted evaluation of adjuvant therapies for operable breast cancer. The International Breast Cancer Study Group. Ann Intern Med 1991;114: 621-628.

3 Reimer T, Hartmann S, Stachs A, Gerber B: Local treatment of the axilla in early breast cancer: concepts from the national surgical adjuvant breast and bowel project b-04 to the planned intergroup sentinel mamma trial. Breast Care 2014;9: DOI: 10.1159/000360411.

4 Halsted WS: I. The results of operations for the cure of cancer of the breast performed at the Johns Hopkins Hospital from June, 1889, to January, 1894. Ann Surg 1894;20:497-555.

5 Giuliano AE, McCall L, Beitsch P, Whitworth PW, Blumencranz P, Leitch AM, et al.: Locoregional recurrence after sentinel lymph node dissection with or without management of the axilla in early breast cancer axillary dissection in patients with sentinel lymph node metastases. Ann Surg 2010; 252:426-433.
6 Rutgers EJ, Donker M, Straver ME, Meijnen P, Van De Velde CJH, Mansel RE, et al.: Radiotherapy or surgery of the axilla after a positive sentinel node in breast cancer patients: final analysis of the EORTC AMAROS trial (10981/22023). J Clin Oncol 2013;31(suppl): abstr LBA1001.

7 Knauer M, Filipits M, Dubsky P: Late recurrences in early breast cancer: for whom and how long is endocrine therapy beneficial? Breast Care 2014;9: DOI: $10.1159 / 000362482$.

8 Davies C, Pan H, Godwin J, Gray R, Arriagada R, Raina $\mathrm{V}$, et al.: Long-term effects of continuing adjuvant tamoxifen to 10 years versus stopping at 5 years after diagnosis of oestrogen receptor-positive breast cancer: ATLAS, a randomised trial. Lancet 2013;381:805-816.

9 Dubsky P, Brase JC, Jakesz R, Rudas M, Singer $\mathrm{CF}$, Greil R, et al.: The EndoPredict score provides prognostic information on late distant metastases in ER+/HER2- breast cancer patients. Br J Cancer 2013;109:2959-2964.

10 Gnant M, Filipits M, Greil R, Stoeger H, Rudas M, Bago-Horvath Z, et al.: Predicting distant recurrence in receptor-positive breast cancer patients with limited clinicopathological risk: using the PAM50 Risk of Recurrence score in 1478 postmenopausal patients of the ABCSG-8 trial treated with adjuvant endocrine therapy alone. Ann Oncol 2014;25:339-345.

11 Pötter R, Gnant M, Kwasny W, Tausch C, HandlZeller L, Pakisch B, et al.: Lumpectomy plus tamoxifen or anastrozole with or without whole breast irradiation in women with favorable early breast cancer. Int J Radiation Oncology Biol Phys 2007; 68:334-340.

12 Maluta S, Dall'Oglio S, Goer DA, Marciai N: Intraoperative electron radiotherapy (IOERT) as an alternative to standard whole breast irradiation: only for low-risk subgroups? Breast Care 2014;9: DOI: $10.1159 / 000362392$.

13 Goldhirsch A, Winer EP, Coates AS, Gelber RD, Piccart-Gebhart M, Thürlimann B, Senn $\mathrm{HJ}$ : Personalizing the treatment of women with early breast cancer: highlights of the St. Gallen International Expert Consensus on the Primary Therapy of Early Breast Cancer 2013. Ann Oncol 2013; 24:2206-2223. 